\title{
Large-scale Soil Maps Improved by Digital Soil Mapping and GIS-based Soil Status Assessment
}

\author{
L. PÁSZTOR, J. SZABÓ, ZS. BAKACSI, P. LÁSZLÓ and M. DOMBOS \\ Research Institute for Soil Science and Agricultural Chemistry (RISSAC) \\ of the Hungarian Academy of Sciences, Budapest
}

\section{Introduction}

Soil surveys, soil maps, spatial soil information systems, spatial soil inference systems are all designed for fulfilling the requirements and demands of society, which have been increasing dramatically in the last decades (MERMUT \& ESWARAN, 2000). Traditional soil survey is time consuming and expensive, new conventional surveys in the near future are very unlikely in the great majority of the world (NACHTERGALE \& VAN RANST, 2002). Nevertheless, the description of (as current as possible) soil status is still strongly needed by various areas of speciality. In the recent digital era spatial soil information systems (SSISs) play a more and more important role in this context (LAGACHERIE \& MCBRATNEY, 2004; ROSSITER, 2004).

In addition, due to the high cost of soil sampling, methods exploiting existing information integrated with techniques providing their refinement have become increasingly important. Digital soil mapping, the application of auxiliary spatial databases of certain predictive environmental covariables are affordable at significantly lower costs (DoBOS et al., 2002; MCKENZIE \& GALLANT, 2005), the introduction and calibration of pedotransfer functions (HUBRECHTS et al., 1998) can facilitate the elaboration of reliable and multi-purpose spatial soil information systems. These tools should integrate traditional pedological knowledge (WALTER et al., 2005) and work with data primarily collected in the field (WEBSTER, 1997).

Essentially the main practical aim of soil surveys and soil maps is prediction (LEENHARDT et al., 1994). It simply means that a certain soil feature is estimated for a whole region based on available soil data collected at localized sample points. The traditional tool of this information extension is the classical soil map using soil mapping units. Crisp soil maps subdivide the region into disjunctive units in a way that within heterogeneity of soil properties is less than for the whole territory (BECKETT \& WEBSTER, 1971). Numerous novel methods have been developed for producing more accurate soil maps; traditional crisp soil maps, however, are still extensively applied, as they offer the most easily interpretable results for the major-

Correspondence to: LÁSZLÓ PÁSZTOR, Research Institute for Soil Science and Agricultural Chemistry of the Hungarian Academy of Sciences, GIS Laboratory, H-1022 Budapest, Herman Ottó út 15. Hungary.E-mail: pasztor@rissac.hu 
ity of users. On the other hand, the accuracy of crisp soil maps is improvable in several ways: with the refinement of soil contours; with the subdivision of mapping units, taking into consideration smaller within patch inhomogeneities; and with the refinement of attributive information (more recent data, more precise measurement, up-to-date methodology, more appropriate classification etc.).

SSISs are usually based on classical soil information converting soil maps and soil profile reports into digital format. Consequently, their spatial accuracy greatly depends on the crisp soil maps used as raw material. Digital soil mapping and GIS environment jointly enable much more, however, than the simple digital reproduction of the information originating from soil surveys.

Digital soil mapping (DSM) integrates the recent developments in numerical soil mapping techniques with the knowledge on soil cover, which has been collected by soil surveyors. DSM is based mainly on the assumption that soil properties are predictable with acceptable accuracy from other environmental parameters of the same location. This is expressed by the so-called SCORPANequation $S=f(S, C, O, R, P$, $A, N$ ), where the 7 factors for soil spatial prediction are: S: Soil properties at the same location; C: Climate; O: Organism; R: Relief; P: Parent material; A: Age, time; N: Geographic position (MCBRATNEY et al., 2003). In practice, three types of soil auxiliary information (in statistical terms "predictors") are used most frequently: remotely sensed images, topographic information and thematic maps interesting for soil mapping. The development of DSM methods has been a growing activity in the past decades (http://www.digitalsoilmapping.org/). DSM with the computational power integrated into modernized GIS packages provides new solutions for the improvement of SSISs.

According to the position paper of ROSSITER (2004) existing SSISs concern mainly regional or national scale (corresponding cartographic scale less than 1:200,000; spatial resolution greater than $400 \mathrm{~m}$ or 16 ha in territorial units). This is not surprising, as even survey data are scarcely available in larger scale. On the other hand, even if more detailed traditional soil information were available, the first initiatives on compiling a complete (e.g. national) SSIS rely on existing, generally small-scale (frequently generalized) soil maps and data. Nevertheless, more detailed SSISs are strongly expected by numerous potential users. The next step would be the level featured by a scale of 1:200,000 up to 1:20,000 (with a nominal spatial resolution of 40-400 $\mathrm{m}$ or $0.16-16$ ha in territorial units) (LAGACHERIE \& MCBRATNEY, 2004). Even the highly developed countries are not always capable of fulfilling the expectations of the worldwide developing spatial data infrastructure (SDI) from soil information point of view, either because the existing soil databases are not exhaustive or precise enough. The European Soil Protection Strategy (CEC, 2002) requires adequate spatial information on soils, which should be organized according to INSPIRE principles (CEC, 2004).

A great amount of soil information is available in Hungary due to former agrogeological surveys. The collected data are accessible in different scales: national, regional, micro-regional, farm and field level, and generally they are related to maps (VÁRALLYAY, 2002). Similarly to the great majority of the world, however, large-scale, comprehensive new surveys cannot be expected in the near future. In 
the 1990s a great part of these, dominantly small-scale, soil related data was converted into digital format and organized into SSISs (SZABÓ \& PÁSZTOR, 1994; VÁRALLYAY et al., 1994, 2000; SzABÓ et al., 1998). Nevertheless, more detailed SSISs are strongly awaited by numerous fields of interests (environmental protection, land evaluation, precision farming etc.). Fitting this requirement, GIS processing of the large-scale practical soil maps is a challenging task in Hungary (PÁszTOR et al., 2002). As of primary importance, the GIS adaptation and digital reambulation of the 1:25,000 scale, practical soil mapping programme - hallmarked by Kreybig is under construction (SZABÓ et al., 2005).

\section{Materials and Methods}

The national soil mapping project initiated and led by Kreybig was unique, being a national, large-scale survey based on field and laboratory soil analyses and at the same time serving practical purposes (KREYBIG, 1937). The practical soil mapping was carried out between 1935 and 1951 in several stages. In the fifties, when the action was successfully completed, Hungary was the first in the world to have such detailed soil information for the whole country (SZABÓ et al, 2000). These maps still represent a valuable treasure of soil information at the present time.

The soil and land use conditions were shown jointly on the maps. Overall chemical and physical soil properties of the soil root zone featuring soil patches were identified for croplands. Three characteristics were attributed to soil mapping units and displayed on the maps. Further soil properties were determined and measured in soil profiles. The unique feature of the Kreybig method is that one representative and further, non-representative soil profiles occurring within the patch are attached to the soil units of the maps. These profiles jointly serve with information on the heterogeneity of the area. Using representative profiles in traditional soil survey is a common solution for linking detailed soil properties originating from soil profiles and the mapping units of crisp soil map representing the pedological variability of land (LEENHARDT et al., 1994). The use of non-representative soil profiles displaying within soil unit, unmappable heterogeneity was a unique approach. The surplus information provided by this methodology can be exploited by the new technology provided by GIS.

The first step of the digital processing of the archives is the "simple" conversion of analogue maps and records into digital format, integrating the data available at various institutions, in different scale and processing level. The map sheets are scanned, spatial data (soil units as polygons and soil profiles as points) are vectorized; a profile database is compiled. The resulted SSIS can be mainly considered as the digitally converted version of the processed map-based soil information. Nevertheless, there are various steps for increasing the spatial and thematic accuracy of soil information stored in this "raw" SSIS. 


\section{Formation of a self-consistent system}

Having completed the geometric and thematic digitization of neighbouring sheets, they are fitted together solving edge correction, and then are merged. At the same time a primary desktop reambulation is carried out. This is necessary because of certain discrepancies experienced in the processed data. Although the survey methodology involved edge correlation between neighbouring sheets, some unmatching soil patches still remained. The reason for such inconsistencies might be that the available raw map material can be on different level of processing, thus the original edge matching efforts vanished in time. Furthermore, discrepancies may be attributed to the temporal shift, which can occur between the independent surveys of even close areas mapped on different sheets. The original analogue maps represented individual cartographic products, which fact hid these inconsistencies, multiple sheets were rarely used in parallel. Even if these types of problems had been detected by certain users they were neither reported nor used for a general improvement of the map series.

\section{Increasing thematic accuracy within appropriate SDI (spatial data infrastructure)}

Obvious changes in land conditions not accounted for in a SSIS may stagger the applicability of the whole database, even if the mapped soil properties have not changed significantly (or generally at all) on the majority of the territory. The integration of spatial soil information within appropriate SDI can help in treating this problem. Reliability and accuracy are increasable by taking into consideration the changes reflected by digitally available recent information on topography and/or land use (remotely sensed images, spatial databases), which are simultaneously used within the same GIS environment. For pilot areas around the country this primary desktop update of the polygon structure has already been carried out. CORINE Land Cover (CLC100, CLC50), orthophotos and forest cadaster were used for the correction. Finalizing this stage, the elaborated Kreybig Digital Soil Information System (KDSIS) can be regarded as a true SSIS even by more rigorous critics (ROSSITER, 2004). Nonetheless there are two further possibilities of increasing the spatial and thematic accuracy of KDSIS.

\section{Spatial refinement of spatial units integrating Kreybig profile methodology and SDI}

The Kreybig survey used representative and non-representative soil profiles occurring within soil patches for the indication of unmappable heterogeneity of the land. The Kreybig Digital Soil Information System (KDSIS) - integrated with spatial themes (DEM, orthophotos etc.) on appropriate environmental factors - can resolve the constraints of traditional mapping. The location of non-representative soil profiles indicates local heterogeneity in soil properties, which frequently can be identified in terrain, land use, and topography. Using significant (sharp) edges, gradients occurring in these covariable spatial themes, new soil boundaries subdividing the original soil mapping units can be outlined. A soil profile regarded as 
non-representative in its former supporting patch becomes the representative profile of the newborn entity. The spatial resolution, as well as the overall accuracy of the system can be increased by this way. This activity also contributes to the conversion of the single scale KDSIS into a multi-level SSIS with an opening to the larger scales.

\section{Updating soil information with recent fieldwork}

Field verification/correlation studies completed with appropriate data collection, and the inclusion of newly accessed data into KDSIS can also significantly increase its reliability. This verification should be carried out by the reambulation of the originally mapped areas and the dug profiles accompanied with new samplings at the revisited sites for assessing current soil status. On the other hand, the appropriate management of KDSIS also makes it possible to elaborate an efficient survey and sampling design, thus making fieldwork quicker and more economic. The stages of field reambulation are as follows:

- Identification of the representative soil profiles sampled during the Kreybig survey to be revisited, taking into consideration all available original information on the survey and recent information on the present status of the sample site.

- Navigation to the location, using the opportunities provided by field GIS.

- Testing the accessibility of the location or assignment of new profile location.

- Determination of the representativity or assignment of new profile location.

- Determination of the acceptability of the site as a new Kreybig profile, based on substandard profile or test boring or assignment of new profile location.

- Detailed site characterization (with digital photo documentation), soil sampling by diagnostic layers and standard profile description for monitoring points. Incidentally further detailed and/or soil related supplementary examinations (hydrophysical properties, soil biota, nutrient status etc.).

\section{Results and Discussion}

The integration of traditional pedological knowledge, KDSIS and field GIS makes soil status assessment and sampling expedient, thus fieldwork becomes quick, efficient and consequently economic. Relatively large regions can be surveyed and characterized by the updated soil properties determined in the revisited or the newly assigned representative profiles whose representative locations are tested and verified in the field. Spatial extension of the information gained in point locations (both measured soil features and/or identified changes) can be carried out based on representativity, thus making the spatial inventory of soil related processes possible.

During its development the different stages of KDSIS provide soil information on different levels of accuracy. This kind of multilevel feature can be preserved and even utilized. Data on a lower development level (and consequently less precise) can be produced and serviced faster, and in some cases time is a more dominant 
factor than spatial and/or thematic accuracy. For smaller scale application "rawer" data might prove to be sufficient and at the same time more economic. Deepening KDSIS and extending its more elaborated levels also involves the opportunity of estimating the accuracy expected on the former levels.

The new samplings at the revisited sites makes it possible to compare archived (and so far stored) and newly surveyed data. Changes in soil properties can be identified. This, on the one hand, should be recorded in the database, thus updating it. On the other hand, trends in soil characteristics and functions can be determined; degradation processes can be recognized and/or forecasted. It can serve as a reference to the study of anthropogenic effects. Joint management and application of multi-temporal spatial soil information within an appropriate relational database management system (RDBMS) and GIS environment makes KDSIS also a spatiotemporal soil information system.

Last, but not least, upgraded KDSIS makes the compilation of up-to-date (crisp) soil maps possible. Mapping units of the old and new maps may differ due to several reasons. Reshaped contours, new soil patches, units with changed attributes may occur on the new map as compared to the old one (Fig. 1). Upgraded soil maps display features of current soil status on a higher confidence level.

\section{Conclusions}

The applicability of the Kreybig Digital Soil Information System (KDSIS) has been proven by numerous applications. MOLNÁR et al. (1999) used KDSIS in habitat mapping, FARKAS et al. (2005) utilized it for the regional extension of results of their modelling work on impacts of different climate change scenarios on soil water regime. PÁSZTOR et al. (2004) employed it in the quantification and mapping of lowland excess water hazard. Very recently KDSIS was applied as base information source within the various task packages (land management planning, water management modelling in the territories of future water reservoirs etc.) of the Action Plan on Flood Prevention and Protection for the Tisza River (SzABÓ \& PÁSZTOR, 2004). The fully loaded KDSIS is suggested to serve as a well-established basis for various further soil related expert systems, as well as to be suitable for the foundation of the soil module of the Hungarian SDI.

The overall elaboration and mainly reambulation process of KDSIS cannot be carried out by a single research institute and needs extra-institutional co-operation, but the common concept should be elaborated in advance. Nevertheless, the framework of the KDSIS and its reambulation methodology has been worked out.

The elaborated environment and methodology is recommended not only in the case of KDSIS, as it could also be applied for the treatment (compilation, refinement, upgrading etc.) of other large-scale SSISs, processing the information collected during large-scale $(1: 10,000)$ practical soil mappings. Depending on the raw material, however, certain specifications in the common framework should be adjusted, which also requires some professional reconciliation and co-operation. 


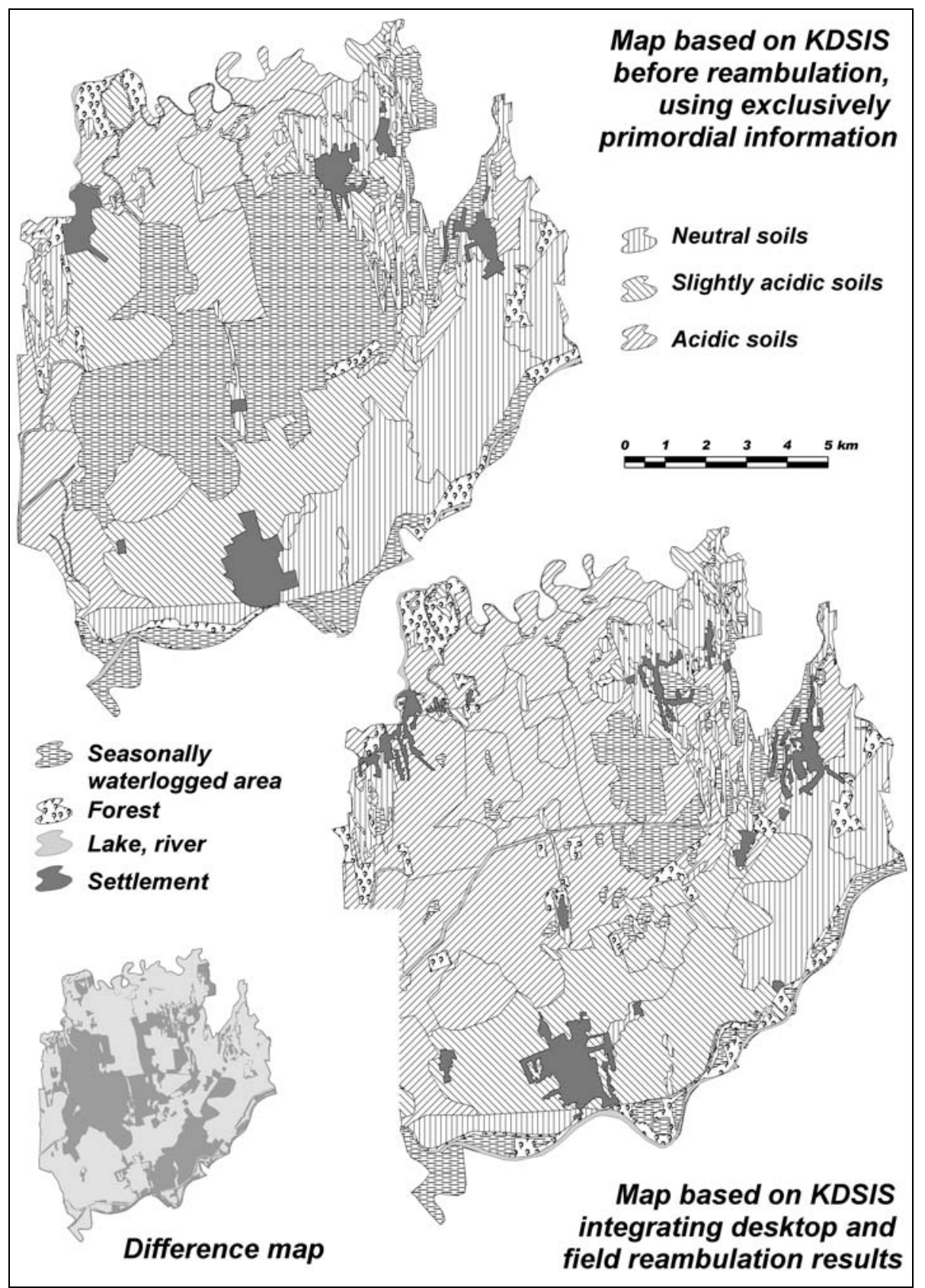

Fig. 1

Map of chemical soil properties for a pilot area based on the Kreybig Digital Soil Information System (KDSIS) before and after the reambulation process.

Areas with differing classification are displayed separately 


\section{Summary}

A key issue of the applicability of both traditional soil maps and soil information systems (SSISs) is their accuracy. Essentially, the main practical aim of soil surveys/mapping and spatial soil information is prediction. A traditional tool of this information extension is the classical (crisp) soil map (using soil mapping units), which generally constitute the geometric basis of SSISs, too. Numerous novel methods have been developed for producing more accurate soil maps, however traditional crisp soil maps are still extensively applied, as they offer the most easily interpretable results for the majority of users. On the other hand, accuracy of this kind of soil maps can be increased in several ways: with the refinement of soil contours; with the subdivision of mapping units taking into consideration smaller, within patch inhomogeneities; and with the refinement of attribute information (more recent data, more precise measurement, up-to-date methodology, more appropriate classification etc.).

The GIS adaptation of soil information originating from the 1:25,000 scale practical soil mapping of Hungary is under construction. Compilation of the Kreybig Digital Soil Information System (KDSIS) involves both its integration within appropriate spatial data infrastructure and updating with efficient field correlation, which make an inherent refinement and upgrading of the system possible. The first attempts for the field-based updating of KDSIS have been done, using field GIS technology. Processes of desktop and field reambulation of the detailed, complex, national spatial soil information system are presented in this paper.

The present work was partly funded by the Hungarian National Scientific Research Fund (OTKA, Grant No. K60896) and the National Research and Development Program (NKFP, Grant No. NKFP6-00013/2005).

Key words: spatial soil information system, reambulation, digital soil mapping, field GIS, soil status assessment

\section{References}

Beckett, P. H. T. \& Webster, R., 1971. Soil variability: a review. Soils and Fertilizers. 34. 1-15.

CEC, 2002. Towards a Thematic Strategy for Soil Protection. Brussels, COM(2002) 179 Final.

CEC, 2004. Proposal for a Directive of the European Parliament and of the Council establishing an infrastructure for spatial information in the Community, $\operatorname{COM}(2004) 516$ Final.

DoBos, E. et al., 2002. The use of DEM and satellite data for regional scale soil databases. Agrokémia és Talajtan. 51. 263-272. 
FARKAS, Cs., RANDRIAMAMPIANINA, R. \& MAJERCAK, J., 2005. Modelling impacts of different climate change scenarios on soil water regime of a Mollisol. Cer. Res. Com. 33. 185-188.

HuBRECHTS, L. et al., 1998. From soil survey to quantitative land evaluation in Belgium. Research Report No. 4. 91-100. European Soil Bureau. Ispra. Italy.

KREYBIG, L., 1937. Soil survey, analysis and mapping method of the Hungarian Royal Institute of Geology. (In Hungarian) M. Kir. Földtani Intézet Évkönyve. 31. 147244.

LAgacherie, P. \& MCBratney, A. B., 2005. Spatial Soil Information Systems and Spatial Soil Inference Systems: Perspectives for digital soil mapping. In: Digital Soil Mapping. (Eds.: Lagacherie, P., McBratney, A. B. \& Voltz, M.) Elsevier Science Publication. In Press.

LEENHARDT, D. et al., 1994. Evaluating soil maps for prediction of soil water properties. European Journal of Soil Science. 45. (3) 293-301.

McBratney, A. B., Mendoça Santos, M. L. \& Minasny, B., 2003. On digital soil mapping. Geoderma. 117. (1-2) 3-52.

McKenzie, N. \& Gallant, J., 2005. Digital soil mapping with improved environmental predictors and models of pedogenesis. In: Digital Soil Mapping (Eds.: Lagacherie, P., McBratney, A. B. \& Voltz, M.). Elsevier Science Publication. In Press.

Mermut, A. R. \& Eswaran, H., 2000. Some major developments in soil science since the mid-1960s. Geoderma 100. (3-4) 403-426.

MOLNÁR, Zs. et al., 1999. Application of habitat mapping in monitoring of biodiversity. (In Hungarian) In: Nemzeti Biodiverzitás-monitorozó Rendszer XI. Élőhelytérképezés. (Eds.: Kun, A. \& MolNÁR, Zs.) 16-19. Sciencia Kiadó. Budapest.

NACHTERGAELE, F. \& VAN RANST, E., 2003. Qualitative and quantitative aspects of soil databases in tropical countries. In: Evolution of Tropical Soil Science: Past and Future. (Ed.: STOOPS, G.) Royal Academy of Overseas Sciences, Brussels. 102114.

PÁSZTOR, L., SZABÓ, J. \& BAKACSI, Zs., 2002. GIS processing of large-scale soil maps in Hungary. Agrokémia és Talajtan. 51. 273-282.

PÁszTOR, L. et al., 2004. Quantifying and mapping lowland excess water hazard. In: Proc. $4^{\text {th }}$ Int. Conf. on Land Degradation (Eds.: FAZ, A., ORTIZ, R. \& GARCIA, G.) Cartagena. CD-ROM.

Rossiter, D. G., 2004. Digital soil resource inventories: status and prospects. Soil Use \& Management. 20. (3) 296-301.

SzABÓ, J. \& PÁSzTOR, L., 1994. The agroecological database of Hungary and its possible application in environment protection. (In Hungarian) In: Országos Környezetvédelmi Konferencia Kiadványa. Siófok.156-163.

SZABÓ, J. \& PÁSZTOR, L., 2004. GIS-based refinement of the KDSIS spatial soil information system in the Bodrogköz region. In: Proc. $5^{\text {th }}$ Int. Conf. on Influence of Anthropogenic Activities on Water Regime of Lowland Territories, Michalovce. CDROM.

SzABÓ, J., PÁszTOR, L. \& BAKACSI, Zs. 2005. National Spatial Soil Information System: Demand, feasibility and construction stages. (In Hungarian) Agrokémia és Talajtan. 54. 41-58. 
SzABÓ, J. et al., 1998. Integration of remote sensing and GIS techniques in land degradation mapping. Agrokémia és Talajtan. 47. 63-75.

SzABÓ, J. et al., 2000. Kreybig Digital Soil Information System (Background, GIS basis). (In Hungarian) Agrokémia és Talajtan. 49. 265-276.

VÁRALLYAY, GY., 2002. Soil survey and soil monitoring in Hungary. In: European Soil Bureau. Research Report No. 9. 139-149. ESB. Ispra.

VÁrAllyay, Gy. et al., 1994. SOTER (Soil and Terrain Digital Database) 1:500,000 and its application in Hungary. Agrokémia és Talajtan. 43. 87-108.

VÁrAllyay, GY. et al., 2000. Soil vulnerability assessments in Hungary. In: Soil and Terrain Database, Land Degradation Status and Soil Vulnerability Assessment for Central and Eastern Europe, FAO Land and Water Digital Media Series 10. (Eds.: BAtJes, N. H. \& BRIDGeS, E. M.) CD-ROM. FAO. Rome.

WALTER, C., LAGACHERIE, P. \& Follain, S., 2006. Integrating pedological knowledge into soil digital mapping. In: Digital Soil Mapping. (Eds.: LAGACHERIE, P., McBratney, A. B. \& Voltz, M.). Elsevier Science Publication. (In Press)

Webster, R., 1997. Soil resources and their assessment. Phil. Trans. R. Soc. Lond. B 352. 963-973. 